30. McConnell R, Berhane K, Yao L, et al. Traffic, susceptibility, and childhood asthma. Environ Health Perspect 2006;114:766-72.

31. Cesaroni G, Badaloni C, Porta D, et al. Comparison between several indices of exposure to traffic-related air pollution and their respiratory health impact in adults. Occup Environ Med 2008;65:683-90.
32. Li N, Hao M, Phalen RF, Hinds WC, et al. Particulate air pollutants and asthma. A paradigm for the role of oxidative stress in PM-induced adverse health effects. Clin Immunol 2003;109:250-65.

33. Kulkarni N, Pierse N, Rushton L, et al. Carbon in airway macrophages and lung function in children. N Engl J Med 2006;355:21-30.

\section{Beware the pregnant woman with breathlessness}

A 32-year-old woman in the 20th week of her third pregnancy was referred to the advanced lung disease service with breathlessness. As a child she could not keep up with the other children and was told that she had a "hole in the heart" but this did not require further investigation or treatment. In previous pregnancies she had been breathless and fatigued from midtrimester and into the postpartum period, but she thought this was a normal change in pregnancy.

Examination revealed a soft systolic murmur and loud second heart sound. Echocardiography showed an abnormal dilated left atrium, mildly dilated right ventricle and an estimated pulmonary artery systolic pressure of $60 \mathrm{~mm} \mathrm{Hg}$, but no evidence of an atrial septal defect, ventricular septal defect or patent ductus arteriosus. VQ (ventilation-perfusion) scan showed no evidence of thromboembolic disease. Highresolution CT chest excluded interstitial lung disease.

Cardiac MRI (fig 1) revealed an unusual cause for her pulmonary hypertension.

\section{QUESTION}

What is the cause of her pulmonary hypertension?

see page 586 for answer.

This case is submitted by:

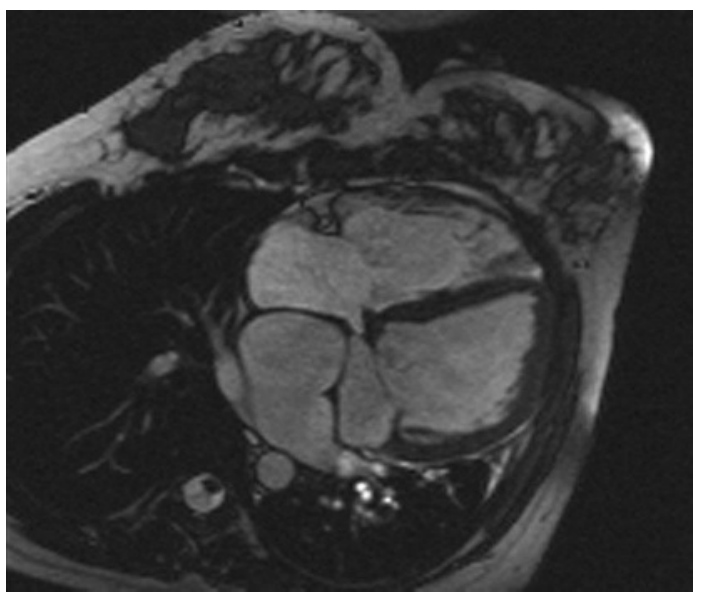

Figure 1 Cardiac MRI-four-chamber view.

\section{A Higton, C Whale, M Musk, E Gabbay}

Advanced Lung Disease Unit, Ainslee House, Royal Perth Hospital, Perth, Western Australia, 6004, Australia

Correspondence to: Dr A Higton, Advanced Lung Disease Unit, Ainslee House, Royal Perth Hospital, Perth, Western Australia,6004, Australia; alexhigton@yahoo.co.uk

Competing interests: None.

Patient consent: Obtained.

Thorax 2009;64:580. doi:10.1136/thx.2008.105353 